\title{
Labour Pain Management with Water Immersion
}

JM Martínez-Galiano

\begin{abstract}
Objective: To determine the effect of water immersion on labour and delivery and on the health of the mother and the newborn.

Methods: An observational study was conducted in primiparous women who had used water immersion during labour at San Juan de la Cruz Hospital, Spain. Statistical analysis was performed using the Chi-square or Fisher's test, Student's t-test or Mann Whitney U test, and analysis of variance (ANOVA) or Kruskal Wallis test. The behaviour of quantitative variables over time was studied with the Student's t-test for paired samples or the Wilcoxon test.

Results: The study included 71 women, with a mean pain score (maximum of 10) of $8.35 \pm 1.32$ immediately before water immersion versus $5.79 \pm 1.8$ after 30 minutes of water immersion $(\mathrm{p}<0.001)$. Deliveries were eutocic in 84.5\%. An Apgar index score of $\geq 7$ at one minute of life was obtained in $98.6 \%$ of the newborns.

Conclusion: Water immersion during labour appeared to be useful in reducing pain and maintaining good health indicators.
\end{abstract}

Keywords: Hydrotherapy, labour, newborn, non-pharmacological analgesic measures, pain, pregnancy

\section{Manejo del dolor durante el trabajo de parto con inmersión en agua}

JM Martínez-Galiano

\begin{abstract}
RESUMEN
Objetivo: Determinar el efecto de la inmersión del agua en el trabajo de parto y el alumbramiento, así como en la salud de la madre y el recién nacido.

Métodos: Se realizó un estudio observacional en mujeres primíparas que habian usado inmersión en el agua durante el trabajo de parto en el Hospital San Juan de la Cruz, España. El análisis estadístico se realizó utilizando la prueba de chi cuadrado o el test exacto de Fisher, la prueba $\mathrm{t}$ de Student (Test-T), la prueba U de Mann-Whitney Prueba de U, y el análisis de la varianza (ANOVA) o la prueba de Kruskal-Wallis. El comportamiento de las variables cuantitativas a través del tiempo se estudió con la prueba t de Student para las muestras pareadas, o el test de Wilcoxon.

Resultados: El estudio incluyó 71 las mujeres, con una puntuación de dolor medio (máximo de 10) de $8.35 \pm 1.32$ inmediatamente antes de la inmersión del agua, en comparación con $5.79 \pm$ 1.8 después de 30 minutos de inmersión en el agua $(\mathrm{p}<0.001)$. Los partos fueron eutócicos en el $84.5 \%$. Una puntuación de índice Apgar de $\geq 7$ en un minuto de vida se obtuvo en el $98.6 \%$ de los recién nacidos.
\end{abstract}

From: Hospital San Juan de la Cruz, Úbeda, Jaén, Spain; Department of Health Sciences, University of Jaen, Spain; and CIBER de Epidemiología y Salud Pública, Ministry of Health, Institute of Health Carlos III, Madrid, Spain.
Correspondence: Dr JM Martínez-Galiano, Universidad de Jaén, Campus de Las Lagunillas s/n, Edificio B3, 23071, Jaén, Spain. Email: juanmimartinezg@hotmail.com 


\section{Conclusión: La inmersión en agua durante el trabajo de parto mostró ser útil para reducir el dolor y mantener buenos indicadores de salud.}

Palabras clave: Hidroterapia, trabajo de parto, recién nacido, medidas analgésicas no farmacológicas, dolor, embarazo

West Indian Med J 2018; 67 (1): 47

\section{INTRODUCTION}

Pain control is one of the responsibilities of the professionals involved in labour and one of the main concerns of pregnant women. Various measures are available for labour pain relief, including epidural analgesia, maternal education, support during labour, dermal injections of sterile serum, or water immersion, although not all have demonstrated effectiveness (1).

Water immersion during labour had demonstrated multiple benefits for both the mother and the newborn and had been described as a useful method in reducing pain (2). Besides relieving their pain, it was also observed that the women participated more actively in the labour process and felt safer, supported and comfortable. In general, women who had undergone water immersion reported a better experience of labour in comparison to those who had not (3). The Cochrane review by Jones et al reached the same conclusions on the positive effects of labour with water immersion (4).

Another Cochrane review related the use of water immersion to a lower use of epidural analgesia and found no evidence of increased adverse effects for the fetus/newborn. There were no differences in newborn hospitalization, Apgar test scores or onset of neonatal infections, and a reduction in pain was reported by the women, most of whom would choose this method in a future pregnancy. The authors found no differences in the delivery, duration of the different periods of labour, degree of perineal tear or frequency of maternal infection (5). Other studies demonstrated that water immersion had reduced the duration of labour $(6,7)$ and that the women were more relaxed and felt more comfortable (8); it had been described as a useful procedure during cervical dilatation (4-9).

Water immersion had also been found to reduce the need for amniotomy and oxytocin perfusion, among other frequent interventions during labour (10). Encouragement of the use of non-pharmacological analgesic measures during labour (eg water immersion) was a priority objective of the World Health Organization (WHO) and other healthcare organizations (11). The objective of this study was to determine the effect of water immersion on labour and delivery and on the health of the mother and the newborn.

\section{SUBJECTS AND METHODS}

A prospective observational study was conducted in women giving birth in San Juan de la Cruz Hospital, Úbeda, Jaén, Spain, between January 1 and June 30, 2014. Study inclusion criteria were: age over 18 years, primiparity, uncomplicated pregnancy, fetus in cephalic position, spontaneous labour onset, active labour stage, between 37 and 42 weeks of gestation, no presence of severe disease requiring newborn hospitalization, no presence of oligohydramnios, no suspicion of intrauterine growth restriction, metrorrhagia, arterial hypertension or diabetes, and water immersion during labour for at least 30 minutes. An inability to communicate in Spanish was the only exclusion criterion. The participants gave informed consent in writing. The study was approved by the Ethics Committee of Jaen, Spain, at its session of December 2013.

A pilot study was conducted to confirm the validity of an ad hoc data-gathering questionnaire. The sample size was estimated by considering the annual rate of 1100 deliveries in the hospital and a power of $80 \%$ to detect differences in the contrast of the null hypothesis $\mathrm{H}_{0}: \mu_{1}=$ $\mu_{2}$ by means of a bilateral Student's $t$-test for two related samples (5.00\% was considered statistically significant). Assuming a mean pain level of 8.18 at immersion onset and 5.45 after 30 minutes of immersion, with a standard deviation of the difference variable of 2.01, it was estimated that seven experimental units were required for the study. A sample size of eight experimental units was selected to allow for an expected dropout rate of $10 \%$. The women were included consecutively in the study.

Information was gathered on the mother (including sociodemographic data), duration of water immersion, cervical dilatation (in $\mathrm{cm}$ ) at the end of the water immersion, labour duration, type of delivery, use of epidural analgesia, administration of oxytocin, early skin-to-skin contact with the newborn $(<1$ hour postpartum and for $\geq 60$ minutes), active participation in the whole labour process (giving point of view, participating in 
decision-making, voicing suggestions etc), perineal tear, postpartum complications, Verbal Numerical Scale (VNS) pain score (12) immediately before and after 30 minutes of water immersion, and degree of maternal satisfaction with the care received during labour (5-point Likert scale). Information on the newborn was also obtained, including weight, Apgar test score (at one and five minutes of life), need for resuscitation and/or hospitalization, and timing of breastfeeding onset. Data were gathered using an ad hoc questionnaire with 37 items, administered after the immediate puerperium $(>2$ hours after delivery) by one of six trained interviewers. Further data were obtained from clinical records.

\section{Procedure}

All women giving birth at the hospital were offered the possibility of water immersion for pain relief during labour unless this was contraindicated (eg induced labour, maternal disease). The bath (150 cm long, 100 $\mathrm{cm}$ wide and $60 \mathrm{~cm}$ deep) was in a dedicated room of $24 \mathrm{~m}^{2}$, where the mother was alone, except for a companion of her choice. The temperature of the water was maintained at $37-38^{\circ} \mathrm{C}$, and the mother was immersed up to her nipples. In accordance with the usual hospital protocol, healthcare professionals attended the mother at appropriate times for fetal heart rate measurement and vaginal examination, among other routine procedures, and whenever their presence was requested by the mother. Oxytocin was administered in cases of delayed cervical dilatation or fetal descent, and epidural anaesthesia was performed if required by the mother. The mother could remain in the bath for as long as she desired until complete cervical dilatation was achieved, unless otherwise indicated (eg presence of bleeding or meconium-stained amniotic liquid or alteration of fetal heartbeat).

\section{Statistical analysis}

After a descriptive statistical analysis of all the study variables, the Chi-square test or Fisher's test was used to compare qualitative variables. The normality of the data distribution of the qualitative variables was checked with the Shapiro Wilks test. The relationship between quantitative and qualitative variables with two modalities was studied by using the Student's t-test for independent samples or the non-parametric Mann Whitney $U$ test. Qualitative variables with three or more modalities were analysed with ANOVA or the non-parametric Kruskal Wallis test. When the results were statistically significant, the corresponding multiple comparisons were analysed. The Student's $t$-test for paired samples or the non-parametric Wilcoxon's test was used to study changes in quantitative variables over time. The time course of pain was analysed using a repeated-measures ANOVA, with time as within-subject factor (measurements before and after water immersion) and administration of oxytocin as between-subject factor. A $p$-value of $<0.05$ was considered statistically significant, and the SPSS V21 statistical program was used for the data analyses.

\section{RESULTS}

Seventy-one women underwent water immersion during their labour for $\geq 30$ minutes. Their mean age was 29.37 \pm 4.60 years; $73.2 \%$ were married; $97.2 \%$ had Spanish nationality and $95.8 \%$ were Caucasian; $23.9 \%$ had tertiary education at university and $29.6 \%$ had completed secondary education; $36.6 \%$ were unemployed and $29.6 \%$ worked in the public sector; and $54.9 \%$ declared a family income of $€ 1000-1999$ a month.

Immediately before the water immersion, the mean VNS pain score (maximum of 10 ) was $8.35 \pm 1.32$ (range: 5-10), and the median score was 8 (maximum of 10). After 30 minutes of water immersion, the mean VNS score was $5.79 \pm 1.8$ (range: $1-9$ ), and the median was $6(p<0.001)$. There was no change in the statistical significance of the difference after adjusting for age, marital status, educational level and oxytocin administration. No statistically significant differences were found in the pain scores before water immersion and after 30 minutes of water immersion as a function of age, marital status or educational level $[p>0.05]$ (Figure).

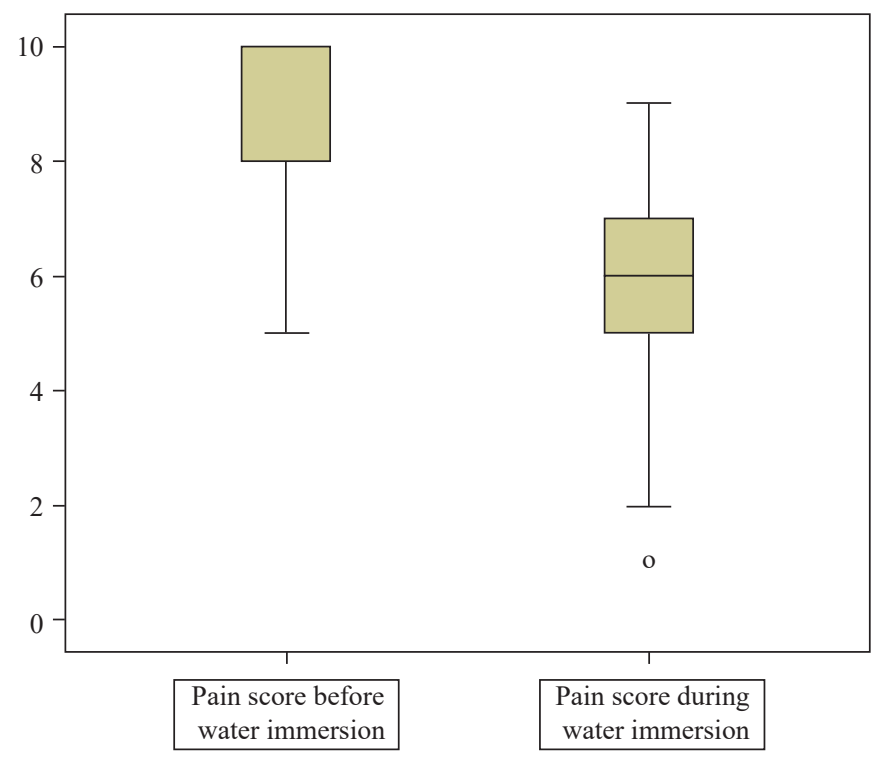

Figure: Pain reported by the woman before and during water immersion during labour. 
The mean cervical dilatation was $4 \mathrm{~cm}$ at the beginning of water immersion. The mean duration of the cervical dilatation stage was $230.18 \pm 126.92$ (range: 55-610) minutes, with a median of 210 minutes; the mean duration of the expulsive stage was $64.39 \pm 56.46$ (range: 10-292) minutes, with a median of 47 minutes; and the mean duration of the delivery stage was 9.62 \pm 7.35 (range: $1-30$ ) minutes, with a median of 8 minutes. There were no statistically significant differences in the duration of these stages as a function of age, marital status or educational level $(p>0.05)$. The delivery was eutocic in $84.5 \%(n=60)$ of the women, instrumental in $9.9 \%(\mathrm{n}=7)$ and by Caesarean section in the remaining $5.6 \%(n=4)$.

Of the 71 women immersed in water for $\geq 30$ minutes during their labour, 94.4\% $(\mathrm{n}=67)$ had early skin-toskin contact with their newborn, and 97.2\% $(\mathrm{n}=69)$ participated actively in the whole process. The Table shows the types of perineal lesion recorded. Oxytocin was not administered during cervical dilatation in $78.9 \%$ $(\mathrm{n}=56)$ of the labours, and epidural analgesia was not required in $73.2 \%(n=52)$. No statistically significant differences were found in the administration of epidural analgesia as a function of age, marital status or educational level $(p>0.05)$. Other non-pharmacological analgesic measures were used by $57.7 \%(\mathrm{n}=51)$ of the women, with no differences as a function of age, marital status or educational level ( $p>0.05)$. A postpartum complication (revision of the uterine cavity) was observed in only one woman.

Table: Perineal lesion produced during labour in women using water immersion

\begin{tabular}{lcr}
\hline Lesion & n (total $=\mathbf{7 1 )}$ & $\mathbf{\%}$ \\
\hline Cervical tear & 1 & 1.4 \\
First degree tear & 9 & 12.7 \\
Second degree tear & 26 & 36.6 \\
Third degree tear & 4 & 5.6 \\
Vaginal tear & 2 & 2.8 \\
Episiotomy & 14 & 19.7 \\
Episiotomy + perineal tear & 3 & 4.2 \\
Episiotomy + prolongation of the episiotomy & 1 & 1.4 \\
No lesion (intact perineum) & 11 & 15.5 \\
\hline
\end{tabular}

The mean weight of the newborns was $3344.37 \pm$ 396.49 (range: $2500-4330$ ) g, with a median of $3280 \mathrm{~g}$. The mean Apgar test score at one minute of life was $8.85 \pm 0.73$ (range: $5-10$ ) with a median of 9 , and the mean Apgar test score at five minutes of life was 9.82 \pm 0.390 (range: 9-10), with a median of 10. An Apgar test score of $\geq 7$ was recorded in $98.6 \%(n=70)$ of the newborns at one minute of life and in $100 \%(n=71)$ at five minutes of life. No resuscitation measure was required at delivery in $88.7 \%(n=63)$ of the newborns; the remaining $11.3 \%(\mathrm{n}=8)$ required aspiration of secretions. Hospitalization in the neonatal unit was not needed by $94.4 \%(n=67)$ of the newborns; the remaining $5.6 \%(n=4)$ were hospitalized for grunting $(n=1)$, hypoglycaemia $(\mathrm{n}=1)$, respiratory distress $(\mathrm{n}=1)$, and hypotonia with hypothermia and grunting $(\mathrm{n}=1)$. Breastfeeding began early ( $<1$ hour postpartum) and effectively in $78.9 \%(\mathrm{n}=56)$ of the newborns.

Of the 71 mothers, $81.7 \%(\mathrm{n}=58)$ reported a high or good level of satisfaction and $15.5 \%(\mathrm{n}=11)$ expressed satisfaction, with only $2.8 \%(\mathrm{n}=2)$ reporting a low level of satisfaction. No statistically significant differences in the level of satisfaction were found as a function of age, marital status or educational level $(p>0.05)$.

\section{DISCUSSION}

This study showed that water immersion was an effective procedure in relieving labour pain, in agreement with most previous investigations $(4-9,13)$. A mean reduction of more than 2.5 points in VNS-evaluated pain was recorded between immediately before and at 30 minutes of water immersion. Moreover, the women were satisfied with the care received and with their labour, in agreement with Cochrane reviews $(3,4)$.

The use of water immersion during labour is compatible with recommended evidence-based clinical practice for optimal healthcare $(11,14,15)$. Thus, most women participated actively in the labour process, as also reported by Lee et al (3). There was early skin-to-skin contact between mother and newborn, and breastfeeding was generally early and effective, confirming findings by Díaz et al (13).

The mean duration of the cervical dilatation stage was four hours, considerably shorter than the mean of around nine hours as reported in a recent study of primiparous women (same characteristics as in our study) with spontaneous labour onset (16). In the present study, water immersion was started when the women were in the active stage of labour (mean cervical dilatation of $4 \mathrm{~cm}$ ) and was maintained for a mean of 60 minutes, which may explain the reduction obtained in the cervical dilatation period. The mean length of the expulsive period was around 64 minutes in our women, comparable to the mean of 45-55 minutes observed by Carlhäll et al in women using water immersion (16). This technique was found to reduce labour duration by Ochiai 
and Gualda (6) and Cluett and Burns (7) but not by a Cochrane review (5).

The use of oxytocin during cervical dilatation was necessary in only $<22 \%$ of the cases. In this regard, Cluett et al concluded that the use of water immersion reduced the need for oxytocin perfusion during labour (10). Epidural analgesia was applied in $26 \%$ of the present mothers, considerably lower than the frequencies of $82 \%$ (17), 78.1\% (18), 67.8\% (19) and 59\% (20) reported in women not using water immersion during labour. In line with our findings, the Cochrane review by Cluett and Burns concluded that the use of water immersion favoured a reduced use of epidural analgesia (5).

The percentage of eutocic deliveries was very high (around 84\%), and the frequency of instrumental and Cesarean-section deliveries was lower than previous reports in Spain of 23\% (21) and 22.2\% (22). One study found that the use of water immersion during labour did not affect the type of delivery (5), although others had associated water immersion with reduced interventions in the delivery (10) and a lower frequency of dystocic deliveries (23). It should be borne in mind that spontaneous labour onset, which favors eutocic delivery, was an inclusion criterion in the present study (24).

In agreement with other investigations (5), there were no important complications in the postpartum period. The episiotomy rate was lower than the maximum WHO recommendation of $30 \%$ (15) and much lower than the rate of $59 \%$ reported in Spanish primiparous women (25). The low incidence of third degree tears and absence of fourth degree tears were similar to previous reports in women who had undergone water immersion during delivery (26).

Apgar test scores were within the normal range at both one and five minutes of life (27), the hospitalization rate was similar to those reported in normal deliveries, and no newborn required advanced resuscitation measures, in agreement with the studies by Cluett and Burns (5) and Ohlsson et al (26).

\section{Strengths and limitations}

The reliability of the study was enhanced by establishing appropriate inclusion and exclusion criteria, providing the interviewers with training and a manual, and performing a pilot study to test the ad hoc questionnaire and interview procedures. Multiparous women were excluded from the study to avoid any influence of their previous experience of labour on the results. Most of the inclusion criteria were those established in the hydrotherapy protocol at the hospital. Inability to communicate in
Spanish was added as the exclusion criterion because of the need to gather data by interview. To study the analgesic effect at delivery of hot water immersion, the women were subjected to different conditions (pain without immersion in hot water and pain during immersion in hot water). In this way, the response could be evaluated as a result of exposure to hot water immersion.

The limitations of the study included the absence of data on the eligible women who did not accept the offer of water immersion; in addition, the influence of confounders could not be ruled out in this observational study. However, a clinical trial was not considered feasible for ethical reasons.

Our results were in line with most of the available evidence: the use of immersion in water did not pose a greater risk to the health of the mother and the newborn.

Water immersion during cervical dilatation appeared to be a useful approach to reducing pain during labour, fulfilling recommended clinical objectives and maintaining good mother-child health indicators.

A policy of using alternative measures (such as water immersion) during labour in all low-risk births as an option for women who want it should be implemented. It is possible to generalize the use of immersion in water to all women, but a new study must be done in women with a delivery that is not low risk.

\section{ACKNOWLEDGEMENTS}

The author would like to acknowledge all the women who collaborated in the study as volunteers and all the interviewers who participated in the collection of data.

\section{AUTHOR'S NOTE}

The author declares no conflict of interest. No specific funding was received for this study.

\section{REFERENCES}

1. Spanish Society of Gynecology and Obstetrics (SEGO). Consensus document. Labor Analgesia. 2010.

2. Muñoz-Sellés E, Vallès-Segalés A, Goberna-Tricas J. Use of alternative and complementary therapies in labor and delivery care: a cross-sectional study of midwives' training in Catalan hospitals accredited as centers for normal birth. BMC Complement Altern Med 2013; 13: 318.

3. Lee SL, Liu CY, Lu YY, Gau ML. Efficacy of warm showers on labor pain and birth experiences during the first labor stage. J Obstet Gynecol Neonatal Nurs 2013; 42: 19-28.

4. Jones L, Othman M, Dowswell T, Alfirevic Z, Gates S, Newburn M et al. Pain management for women in labour: an overview of systematic reviews. Cochrane Database Syst Rev 2012; 3: CD009234 (article number).

5. Cluett ER, Burns E. Immersion in water in labour and birth. Cochrane Database Syst Rev 2009; 2: CD000111 (article number).

6. Ochiai AM, Gualda DMS. The shower as measure of pain relief in labor. In: International Conference on the Humanization of Childbirth, November 2-4, 2000, Fortaleza, Ceará. Fortaleza: JICA; 2000, p. 75. 
7. Cluett ER, Burns E. Immersion in water in labour and birth. Sao Paulo Med J 2013; 131: 364.

8. Medina ET. Impact of the warm bath to reduced time of labor. In: International Conference on the Humanization of Childbirth, November 2-4, 2000, Fortaleza, Ceará. Fortaleza: JICA; 2000, p. 76.

9. Davim RMB, Torres GV, Melo ES. Non-pharmacological strategies on pain relief during labor: pre-testing of an instrument. Rev Latino-Am Enfermagem 2007; 15: 1150-6.

10. Cluett ER, Pickering RM, Getliffe K, St George Saunders NJ. Randomised controlled trial of labouring in water compared with standard of augmentation for management of dystocia in first stage of labour. BMJ 2004; 328: 314

11. Ministry of Health and Social Policy. Clinical guidelines on the management of normal delivery. $1^{\text {st }}$ edition. Vitoria: Central Publications Service of the Basque Government; 2010.

12. Pardo P, Muñoz T, Chamorro C. Monitoring pain. Work group recommendations for analgesia and sedation of the SEMICYUC. Med Intensiva 2006; 30: 379-85.

13. Díaz Domínguez L, Romero Ariza AE, Lemus Mas R, Consuegra Yañez MA, Guzmán García A, Rivera Sánchez B. Hydrotherapy in the San Cecilio University Hospital of Granada. In: VI Meeting and Second International Congress of the Andalusian Association of Midwives. Seville: Andalusian Association of Midwives, 2013, p. 75.

14. Department of Health of the Government of Andalusia. Best practices in perinatal care: plan of humanization of perinatal care in Andalusia. $1^{\text {st }}$ edition. Seville: Department of Health of Andalusia; 2008.

15. Technical Working Group, World Health Organization. Care in normal birth: a practical guide. Department of Reproductive Health and Research, World Health Organization, Geneva; 1996.

16. Carlhäll S, Källén K, Blomberg M. Maternal body mass index and duration of labor. Eur J Obstet Gynecol Reprod Biol 2013; 171: 49-53.

17. Sabaté S, Gomar C, Canet J, Fernández C, Fernández M, Fuentes A. Obstetric anesthesia in Catalonia (Spain). Med Clin 2006; 126 (Suppl 2): $40-5$.
18. Fernández-Guisasola J, Rodríguez Caravaca G, Serrano Rodríguez ML, Delgado González T, García del Valle S, Gómez-Arnau JI. Obstetric epidural analgesia: relationship to various obstetric variables and the evolution of labor. Rev Esp Anestesiol Reanim 2004; 51: 121-7.

19. Hernández Martínez A, Melero Jiménez MR, Sanabria Martínez G, Casasús Güémez MJ, García Alcaraz F. Epidural analgesia in labor: choice of pregnant women and some repercussions of its application. Matronas Prof 2003; 4: 30-6.

20. Ruiz FJ, Lacal JF, De Prado M, Gomáriz MJ, Rodríguez MI, Castellano FD. Epidural and delivery. Obstetric and perinatal outcomes. Matronas Prof 2001; 2: 27-30.

21. Aceituno-Velasco L. Instrumental delivery rate in Spain. Prog Obstet Ginecol 2009; 52: 609-15.

22. Ministry of Health and Consumption (now the Ministry of Health, Social Services and Equality), Spain. NHS Quality Agency. Institute for Health Information. Pilot study, key indicators. Ministry of Health and Consumption; 2005.

23. Lukasse M, Rowe R, Townend J, Knight M, Hollowell J. Immersion in water for pain relief and the risk of intrapartum transfer among low risk nulliparous women: secondary analysis of the birthplace national prospective cohort study. BMC Pregnancy Childbirth 2014; 14: 60.

24. Hernández Martínez A, Pascual Pedreño AI, Baño Garnés AB, Melero Jiménez MR, Molina Alarcón M. Differences in Cesarean sections between spontaneous and induced labour. Rev Esp Salud Publica 2014; 88: $383-93$.

25. Melchor JC, Bartha JL, Bellart J, Galindo A, Miño M, Perales A. Episiotomy in Spain. Data for 2006. Prog Obstet Ginecol 2008; 51: 559-63.

26. Ohlsson G, Buchhave P, Leandersson U, Nordstrom L, Rydhstrom H, Sjolin I. Warm tub bathing during labor: maternal and neonatal effects. Acta Obstet Gynecol Scand 2001; 80: 311-4.

27. Behrman RE, Kliegman RM, Jenson HB. Textbook of pediatrics. Madrid, Spain: Elsevier; 2004. 